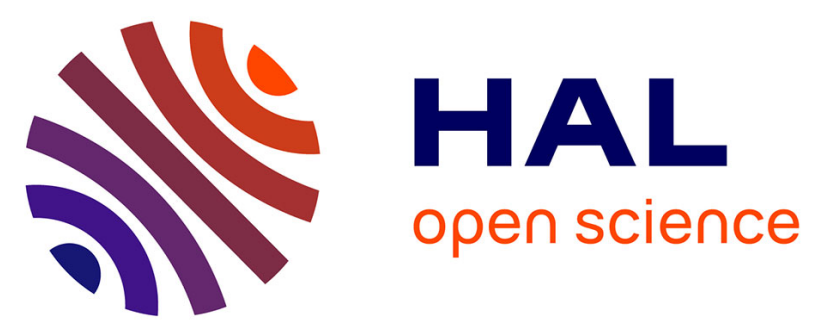

\title{
Judd-Ofelt analysis and crystal field calculations of Er3+ ions in new oxyfluorogermanotellurite glasses and glass-ceramics
}

Hayat Zanane, Matias Velázquez, Dominique Denux, Jean-René Duclère, Julie Cornette, Aïcha Kermaoui, Hamid Kellou, Michel Lahaye, Sonia Buffiere

\section{To cite this version:}

Hayat Zanane, Matias Velázquez, Dominique Denux, Jean-René Duclère, Julie Cornette, et al.. JuddOfelt analysis and crystal field calculations of Er3+ ions in new oxyfluorogermanotellurite glasses and glass-ceramics. Optical Materials, 2020, 100, 109640 (8 p.). 10.1016/j.optmat.2019.109640 . hal-02429359

\section{HAL Id: hal-02429359 \\ https://hal.science/hal-02429359}

Submitted on 6 Jan 2020

HAL is a multi-disciplinary open access archive for the deposit and dissemination of scientific research documents, whether they are published or not. The documents may come from teaching and research institutions in France or abroad, or from public or private research centers.
L'archive ouverte pluridisciplinaire HAL, est destinée au dépôt et à la diffusion de documents scientifiques de niveau recherche, publiés ou non, émanant des établissements d'enseignement et de recherche français ou étrangers, des laboratoires publics ou privés. 


\title{
Judd-Ofelt analysis and crystal field calculations of $\mathrm{Er}^{3+}$ ions in new oxyfluorogermanotellurite glasses and glass-ceramics
}

\author{
Hayat Zanane*,a,c ${ }^{*}$ Matias Velázquez ${ }^{\mathrm{b}}$, Dominique Denux ${ }^{\mathrm{a}}$, Jean-René Duclère ${ }^{\mathrm{d}}$, Julie Cornette ${ }^{\mathrm{d}}$, Aïcha \\ Kermaoui $^{\mathrm{c}}$, Hamid Kellou ${ }^{\mathrm{c}}$, Michel Lahaye ${ }^{\mathrm{e}}$, Sonia Buffière ${ }^{\mathrm{a}}$ \\ ${ }^{a}$ CNRS, Université de Bordeaux, ICMCB, UMR 5026, 87 avenue du Dr. A. Schweitzer, 33608 Pessac cedex, France \\ ${ }^{b}$ Univ. Grenoble Alpes, CNRS, Grenoble INP, SIMAP, 38000 Grenoble, France \\ ${ }^{c}$ Faculté de Physique, Laboratoire d'Électronique Quantique, USTHB, BP 32 El alia, 16111 Bab Ezzouar, Alger, Algeria \\ ${ }^{d}$ IRCER - Centre Européen de la Céramique - 12 Rue Atlantis - 87068 LIMOGES Cedex Atlantis, Limoges, France \\ e PLACAMAT, UMS 3626, CNRS-Université Bordeaux, 87 avenue du Dr. A. Schweitzer, 33600 Pessax
}

Keywords: Glass materials

$\mathrm{Er}^{3+}$ ion spectroscopy

Rare-earth materials

Optical glass-ceramics

\begin{abstract}
New $30 \mathrm{GeO}_{2}-30 \mathrm{TeO}_{2}-15 \mathrm{ZnO}-10 \mathrm{Na}_{2} \mathrm{CO}_{3}-10 \mathrm{CaF}_{2}-3 \mathrm{La}_{2} \mathrm{O}_{3}-\mathrm{x} \mathrm{ErF}_{3}(\mathrm{x}=2$, 4) glasses have been synthesized and submitted to varied heat treatments to provoke nanocrystallization in their matrix. The $\mathrm{Er}^{3+}$-doped materials containing typically $50 \AA$ sized nanocrystallites have been characterized by DSC, ultrapicnometry, XRD, HRTEM, EDS, SAED, optical spectroscopy and VSM techniques. A Judd-Ofelt analysis could be performed from the absorption spectra and led to refined intensity parameters. The local structural changes around $\mathrm{Er}^{3+}$ cations were mostly evidenced by important modifications of the hypersensitive optical absorption bands $\left({ }^{4} \mathrm{I}_{15 / 2} \rightarrow{ }^{2} \mathrm{H}_{11 / 2}\right.$, ${ }^{4} \mathrm{I}_{15 / 2} \rightarrow{ }^{4} \mathrm{G}_{11 / 2}$ ) and lesser modifications of the emission cross sections and experimental lifetimes. Besides, cycling around the crystallization temperature with a VSM showed some kind of "crossover" between the Curie-Weiss behavior of the $\mathrm{Er}^{3+}$ cations dissolved in the glass and those dissolved in the nanocrystallites, with a striking change of magnetic interactions sign from anti- to ferromagnetic. The crystal field Hamiltonian could be refined in $\mathrm{C}_{2}$ symmetry, thanks to the emission and excitation spectra recorded at $80 \mathrm{~K}$, and the crystal field strength calculated.
\end{abstract}

\section{Introduction}

The development of new optical materials easy to synthesize, inexpensive and with remarkable physicochemical and optical properties continues to evolve. Among the great diversity of materials families that exist, the rare-earth-doped oxyfluorinated nanostructured glass-ceramics meet all of the above criteria [1-5]. Tellurite-based glasses are known for their low melting point, infrared transparency and good thermal and mechanical stability [6]. The addition of $\mathrm{GeO}_{2}$ in tellurite glasses increases chemical durability, UV-visible transmission and improves the thermal stability while decreasing the refractive index of the glass [7-9]. $\mathrm{Er}^{3+}$ iondoped transparent glass-ceramics have been given special attention because of their outstanding optical properties which can be tuned according to the application foreseen, such as solid lasers, planar waveguide amplifiers for dense wavelength division multiplexing (DWDM), and optical gratings [10-18]. Indeed, $\mathrm{Er}^{3+}$ is one of the most efficient ions to obtain infrared emission in the 1.53-1.6 $\mu \mathrm{m}$ "eye safe" spectral range, which is very important for the manufacture of lasers for telemetry [19-21].
In this work, $\mathrm{Er}^{3+}$-doped oxyfluorogermanotellurate matrix were synthesized to try to obtain a material with both optical properties close to those of fluorinated single crystals and physico-chemical properties and transparency of the precursor glasses. The intensity parameters $\left(\Omega_{2,4,6}\right)$ and the spectroscopic parameters $\left(\beta, \tau_{\text {rad }}, A_{\mathrm{DE}}, \mathrm{A}_{\mathrm{DM}}\right)$ related to the laser performance were evaluated from the experimental data by the normalized Judd-Ofelt method. Crystal field strength around $\mathrm{Er}^{3+}$ cations and its impact on $4 \mathrm{f}^{6}$ electrons energy level diagram were obtained by means of a parameterized Hamiltonian refined with emission and excitation spectra recorded at $80 \mathrm{~K}$. The $\mathrm{Er}^{3+}$-doped oxyfluorogermanotellurite glasses have been synthesized and submitted to thermal annealing in order to induce the nucleation of nanocrystals, possibly of $\mathrm{CaF}_{2}$ and doped with $\mathrm{Er}^{3+}$ ions. The materials were characterized by differential scanning calorimetry (DSC), ultrapicnometry, Xray diffraction (XRD), high-resolution transmission electron microscopy (HRTEM), energy dispersive spectroscopy (EDS), elected area electron diffraction (SAED), electron probe microanalysis/wavelength dispersion spectroscopy (EPMA/WDS), optical spectroscopy and vibrating sample method magnetometry (VSM).

\section{Experimental}


The samples were prepared with the following composition (in $\mathrm{mol} \%$ ): $30 \mathrm{GeO}_{2}-30 \mathrm{TeO}_{2}-15 \mathrm{ZnO}-10 \mathrm{Na}_{2} \mathrm{CO}_{3}-10 \mathrm{CaF}_{2}-3$ $\mathrm{La}_{2} \mathrm{O}_{3}-\mathrm{x} \mathrm{ErF}_{3}$ (with $\mathrm{x}=2$ or $\mathrm{x}=4$ ). The glasses were elaborated by conventional melting, the starting powders being weighed in the desired amounts according to the selected compositions with an accuracy of $\pm 1 \mathrm{mg}$. After grinding, the powders were placed in a covered platinum crucible and melted for $1 \mathrm{~h}$ at $1323 \mathrm{~K}$. The melts were then rapidly quenched into a preheated stainless steel thin plate at $\mathrm{T}_{\mathrm{g}}-20 \mathrm{~K}$ to avoid thermal shock. The glass was subsequently heat-treated at $\mathrm{T}_{\mathrm{g}}-20 \mathrm{~K}$, in order to relax the mechanical stresses arising from the quenching. Finally, the glasses were polished for structural, optical and spectroscopic measurements. As suggested by DSC measurements (Fig. 1), the as-prepared oxyfluoride glasses were heat-treated at $728 \mathrm{~K}(2 \mathrm{~h})$ to obtain transparent glassy ceramics. The Er contents were determined by EDS and EPMA/WDS. In the remainder of this paper, we shall use an average concentration of $5.288 \times$ and $10.349 \times 10^{20} \mathrm{Er}^{3+} \mathrm{cm}^{-}$ 3 for the $2 \%$ - and 4\%-doped oxyfluoride samples, respectively. The composition of the glasses $(\mathrm{Na}, \mathrm{Ca}, \mathrm{Zn}, \mathrm{Ge}$, Te, La, O, F) was determined by EPMA/WDS, in order to allow for the energy resolution of the $\mathrm{Ca}-\mathrm{K}_{\alpha}(3.691 \mathrm{keV})$ and Te- $\mathrm{L}_{\alpha}$ lines $(3.769 \mathrm{keV})$, and of $\mathrm{F}-\mathrm{K}_{\alpha}(0.677 \mathrm{keV})$ and $\mathrm{La}-\mathrm{M}$ lines $(0.833 \mathrm{keV}$, even if for La we used the $\mathrm{L}$ line at 4.651 $\mathrm{keV})$. The main differences observed between the initial and the final compositions (see Table 1 of the supplementary information file, hereafter called SI) are likely to be due to losses by sublimation and volatilization of $\mathrm{TeO}_{2}$ during the melting stage of the precursor glass (the vapour pressure of $\mathrm{TeO}_{2}$ is higher than $0.3 \mathrm{~atm}$ at temperatures higher than $905 \mathrm{~K}$ [22-23]). The differences between initial and final $\mathrm{F}$ contents are likely to be due to the oxidation of $\mathrm{ErF}_{3}$ and $\mathrm{CaF}_{2}$ in air at high temperature.

The differential thermal analysis of the glasses were performed by means of a differential thermal analyzer DTA Model SDT Q600 TA instrument, with a heating rate of 10 $\mathrm{K} / \mathrm{min}$. The samples were heated in alumina crucibles from room temperature to $1400 \mathrm{~K}$ under $\mathrm{N}_{2}$ atmosphere with a 100 $\mathrm{ml} / \mathrm{min}$ flow. The X-ray diffraction was carried out in a powder diffractometer (PANalytical X'pert Pro) in the $2 \theta$ range $10-80^{\circ}$ with $\mathrm{Cu} \mathrm{K}_{\alpha}$ radiation $(\lambda=1.54056 \AA)$ generated at $40 \mathrm{kV}$ and $30 \mathrm{~mA}$. The transmission spectra were recorded by means of a UV-Vis-NIR VARIAN Cary 5000 spectrophotometer in the 400-2000 nm spectral range. The IR absorption spectra were measured with a BRUKER Equinox 55 spectrophotometer. Density measurements were performed by ultrapycnometry using a Helium QUANTACHROME Ultrapyc 1200e Pycnometer. We found the density by averaging over sixty measurements. We performed three measurement runs for each sample. Each measurement run gave us twenty values, taking three minutes to measure each value. The density of the 2 and $4 \mathrm{~mol} \% \mathrm{Er}^{3+}$-doped glasses is 4.652 and $4.808 \mathrm{~g} / \mathrm{cm}^{3}$, respectively.

We used a high-resolution transmission electron microscope (HRTEM, JEM-2200FS) equipped with energy dispersive spectrometer (EDS) system to try to analyze the microstructure and the elements' distribution of heat-treated glasses, but the samples proved to be unstable under the beam both onto a standard or a cryogenic (105 K) sample holder.

The magnetic susceptibility was measured in field heated and cooled modes $(10 \mathrm{~K} / \mathrm{mn})$ using an EZ-7 MICROSENSE Vibrating Sample Magnetometer operated in the 295-923 K temperature range under an applied magnetic field of $1 \mathrm{~T}$. Two glass samples of mass $50 \mathrm{mg}$ and $11.7 \mathrm{mg}$ were cemented on a quartz rod, the diamagnetic contribution of which was also measured and subtracted from our data. When arrived at the highest temperature selected for each sample, a 15 minutes stage was imposed to the sample and then, the measurement in cooling mode was started. The visible (550 $\mathrm{nm})$ and near IR (950-1700 $\mathrm{nm}$ ) fluorescence spectra were measured with a Horiba Jobin Yvon Fluorolog spectrometer at $80,120,200 \mathrm{~K}$ and room temperature in ambient atmosphere, under Xe lamp illumination. Selected decay times were recorded at $80,120,200 \mathrm{~K}$ and room temperature in the visible and NIR spectral range by exciting the sample at 380 $\mathrm{nm}$ for the ${ }^{4} \mathrm{~S}_{3 / 2} \rightarrow{ }^{4} \mathrm{I}_{15 / 2} \mathrm{Er}^{3+}$ transition and at $650 \mathrm{~nm}$ for the ${ }^{4} \mathrm{I}_{13 / 2} \rightarrow{ }^{4} \mathrm{I}_{15 / 2},{ }^{4} \mathrm{I}_{11 / 2} \rightarrow{ }^{4} \mathrm{I}_{15 / 2} \mathrm{Er}^{3+}$ transitions. An estimate of the linear refractive index was performed by extraction from the experimental data of optical transmission in the spectral range of constant optical transparency of the samples, 1900-2000 nm. We used the Fresnel's expression relating optical transmission coefficient and linear refractive index $\left(\mathrm{T}=2 \mathrm{n} /\left(\mathrm{n}^{2}+1\right)\right)$. The linear refractive index obtained is 1.87 and this value, which will be used in the remainder of this paper, is generally in good agreement with the literature for germano-tellurite glass [24-25].

\section{Results and discussion}

\subsection{Thermal stability of G-GTOF glasses}

The DSC thermogram recorded on the $30 \mathrm{GeO}_{2}-30 \mathrm{TeO}_{2}-15$ $\mathrm{ZnO}-10 \mathrm{Na}_{2} \mathrm{CO}_{3}-10 \mathrm{CaF}_{2}-3 \mathrm{La}_{2} \mathrm{O}_{3}-2 \mathrm{ErF}_{3}$ base glass is shown in Figure 1. The characteristic temperatures were determined to be: transition temperature $\mathrm{T}_{\mathrm{g}}=686 \mathrm{~K}$, starting point of crystallization temperature $\mathrm{T}_{\mathrm{X}}=732 \mathrm{~K}$, crystallization temperature $\mathrm{T}_{\mathrm{c}}=745 \mathrm{~K}$ and $\Delta \mathrm{T}=\mathrm{T}_{\mathrm{X}}-\mathrm{T}_{\mathrm{g}}=47 \mathrm{~K}$, the latter being the thermal stability criterion against crystallization. 


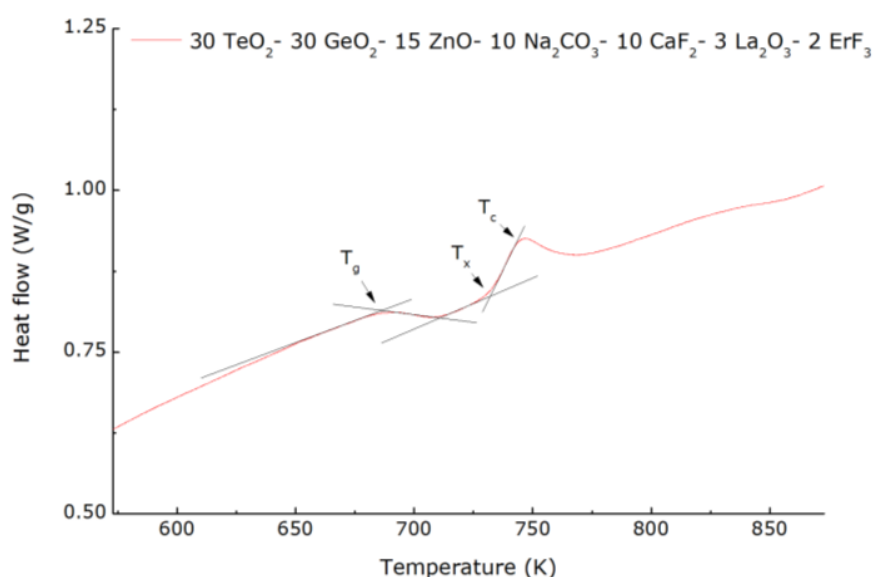

Figure 1. DSC curve of the $30 \mathrm{GeO}_{2}-30 \mathrm{TeO}_{2}-15 \mathrm{ZnO}-10$ $\mathrm{Na}_{2} \mathrm{CO}_{3}-10 \mathrm{CaF}_{2}-3 \mathrm{La}_{2} \mathrm{O}_{3}-2 \mathrm{ErF}_{3}$ glass samples prepared in this study.

The characteristic temperatures of the $30 \mathrm{GeO}_{2}-30 \mathrm{TeO}_{2}-15$ $\mathrm{ZnO}-10 \mathrm{Na}_{2} \mathrm{CO}_{3}-10 \mathrm{CaF}_{2}-3 \mathrm{La}_{2} \mathrm{O}_{3}-2 \mathrm{ErF}_{3}$ glass are similar to what we had in the same composition doped $2 \% \mathrm{Yb}^{3+}$ [26], and to what has been published in similar studies [27-28]. The exothermic phenomenon from $745 \mathrm{~K}$ is due to the crystallization of the $\mathrm{CaF}_{2}$ phase. As mentioned before, based on the results of the thermal analysis we treated the precursor glasses for 2 hours at $728 \mathrm{~K}$ to obtain transparent glassy ceramics.

\section{$3.2 X$-ray diffraction (XRD) on thermally treated glasses}

The heat treatment at $728 \mathrm{~K}$ causes the partial crystallization of the precursor glasses (see in Figure 2). The peaks of crystallization obtained in the " $2 \mathrm{ErF}_{3}$ "-doped glass comes from the crystallization of the $\mathrm{CaF}_{2}$ cubic phase Fm-3m [29]. In Figure 2, we mention the (hkl) indices corresponding to the Fm-3m cubic phase of $\mathrm{CaF}_{2}$. The relative intensity of the (220) diffraction peak is much lower, as compared to that of the (111), than in the pure $\mathrm{CaF}_{2}$ crystallized phase. Provided that preferential orientation effects can be discarded to account for this, by measuring the samples in powder form, the change in diffraction peak relative intensities might be ascribed to partial substitution of $\mathrm{Ca}^{2+}$ cations for $\mathrm{RE}^{3+}$ ones. The size of the crystallites calculated by the Scherrer relation $\mathrm{L}=\lambda /(\beta \times \cos (\theta))$ (with $\mathrm{L}$ the size of the crystallites in $\mathrm{nm}$, $\lambda=1.54056 \AA, \beta$ the integral width of the diffraction peak in radians and $\theta$ the Bragg angle $\left({ }^{\circ}\right)$ ) [30], is on the order of 5 $\mathrm{nm}$, in the "2 $\mathrm{ErF}_{3}$ "-doped sample. Other unidentified diffraction peaks appear on the diffractogram of the " $4 \mathrm{ErF}_{3}$ "doped glass. This might mean that the crystallization temperature of the "pure" $\mathrm{CaF}_{2}$ phase was exceeded, because it is well known that its nucleation temperature decreases with the F-content in the matrix [31-32].

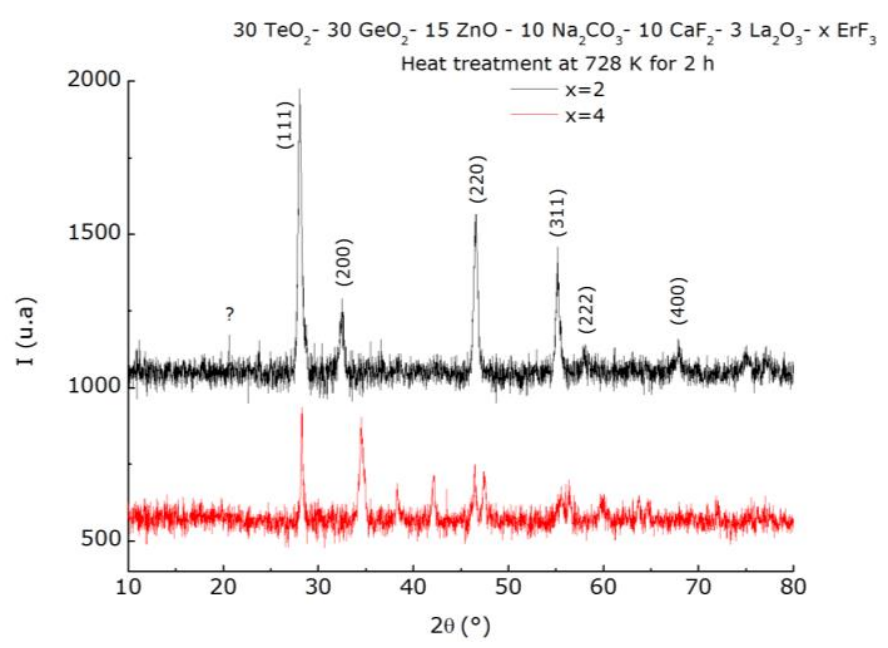

Figure 2. X-ray diffraction patterns of two heat-treated glasses. The indexation mentioned in the black diffractogram corresponds to the Miller indices of the $\mathrm{CaF}_{2}$ cubic phase Fm$3 m$

\subsection{High-resolution transmission electron microscopy (HRTEM), selected area electron diffraction (SAED) and EDS analysis of heat- treated $\mathrm{Er}^{3+}$-doped glass}

The SI file (Fig. 1) gives TEM and HRTEM images together with the SAED pattern of a " $2 \mathrm{ErF}_{3}$ "-doped and heat-treated sample at $728 \mathrm{~K}$ for $2 \mathrm{~h}$. The HRTEM contrast analysis of this sample revealed the presence of nanocrystallites, which was confirmed by SAED spots. The EDS quantitative analysis based on the Er element M-line led to an amount of 0.9 to 2 at. \% over the five crystallized zones investigated. However, these nanocrystallites could not be studied in details because they evolved under the electron beam. From a chemical point of view, all samples were found to be homogeneous (no $\mathrm{Ca}$ "contrast" as the one established, for instance, in [26]) over five mappings.

\subsection{Absorption spectroscopy and Judd-Ofelt analysis}

Figure 3 shows the absorption cross section of $\mathrm{Er}^{3+}$-doped and heat-treated glasses. The absorption bands correspond to transitions between the spin-orbit multiplets ground state ${ }^{4} \mathrm{I}_{15 / 2}$ to the 13 excited states ${ }^{4} \mathrm{I}_{13 / 2},{ }^{4} \mathrm{I}_{11 / 2},{ }^{4} \mathrm{I}_{9 / 2},{ }^{4} \mathrm{~F}_{9 / 2},{ }^{4} \mathrm{~S}_{3 / 2},{ }^{2} \mathrm{H}_{11 / 2},{ }^{4} \mathrm{~F}_{7 / 2}$, 
${ }^{4} \mathrm{~F}_{5 / 2},{ }^{4} \mathrm{~F}_{3 / 2},{ }^{2} \mathrm{H}_{9 / 2},{ }^{4} \mathrm{G}_{11 / 2},{ }^{4} \mathrm{G}_{9 / 2}$ and ${ }^{2} \mathrm{~K}_{15 / 2}$. The absorption peak cross section values are typical of forced electric-dipole and/or magnetic-dipole induced optical transitions and the width of the absorption bands reflects the inhomogeneous broadening of the $\mathrm{Er}^{3+}$ ions transitions in the samples [33]. By superimposing the spectra of the four samples ( $x=2$ and $x=4$, untreated and heat-treated, see Section 2), it happens that the only absorption bands which exhibit a modification in cross section value (the width and peak positions remaining unchanged) are the ${ }^{4} \mathrm{I}_{15 / 2} \rightarrow{ }^{2} \mathrm{H}_{11 / 2}$ and ${ }^{4} \mathrm{I}_{15 / 2} \rightarrow{ }^{4} \mathrm{G}_{11 / 2}$. This means that both heat-treatment and increase in $\mathrm{Er}^{3+}$-content modify selectively the odd components of the crystal field around $\mathrm{Er}^{3+}$ cations in these samples. This variation suggests a modification of the crystal field around $\mathrm{Er}^{3+}$ cations.

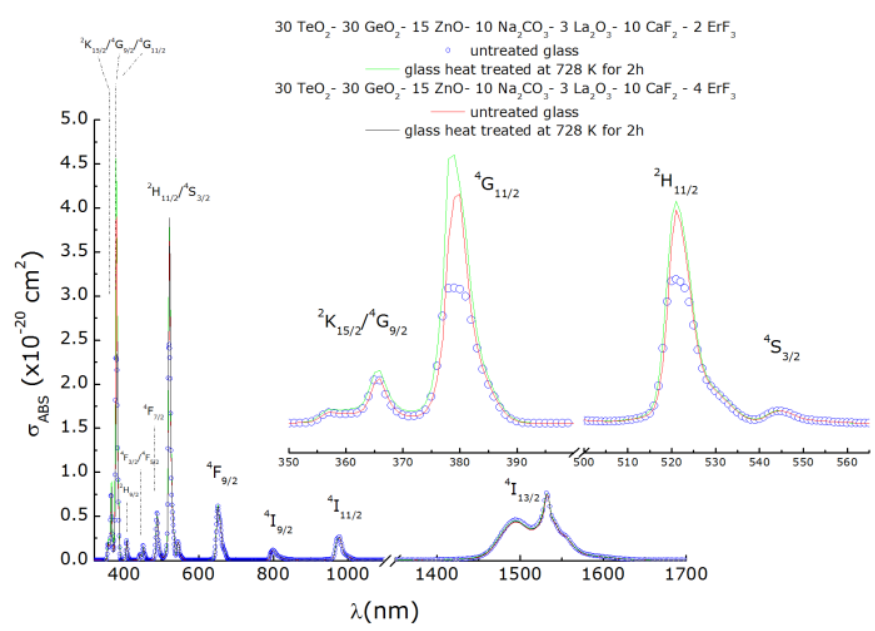

Figure 3. Absorption cross sections of the four glasses and glassy ceramics investigated in this study (see Section 2. Experimental). The insert is a zoom over the two pseudoquadrupolar hypersensitive transitions of the $\mathrm{Er}^{3+} 4 f^{11}$ electronic configuration.

The integrated absorption cross section of each transition can be used as input data to perform Judd-Ofelt analysis [34-45], which is necessary to obtain transition probabilities, branching ratios and radiative lifetimes. The latter two are necessary for calibrating the emission spectra in cross section units by the Fuchtbauer-Ladenburg (FL) method. Each of the absorption bands were integrated in order to perform Judd-Ofelt analysis according to both the normalized procedure of Goldner [4648] and the unnormalized procedure, with and without the thermalized ${ }^{4} \mathrm{~K}_{15 / 2-}{ }^{4} \mathrm{G}_{9 / 2}{ }^{4} \mathrm{G}_{11 / 2}$ levels bands, and in all cases with thermalized ${ }^{2} \mathrm{H}_{11 / 2}$ and ${ }^{4} \mathrm{~S}_{3 / 2}$ levels (Table 1). Since the only transitions which have a $U^{(2)} \neq 0$, or a $U^{(2)}$ matrix element 10 to 100 times higher than the $\mathrm{U}^{(2)}$ ones of the other transitions, are the "pseudo-quadrupolar" hypersensitive ones
${ }^{4} \mathrm{I}_{15 / 2} \rightarrow{ }^{2} \mathrm{H}_{11 / 2}$ and ${ }^{4} \mathrm{I}_{15 / 2} \rightarrow{ }^{4} \mathrm{G}_{11 / 2}$ ones [47-48], and since the ${ }^{4} \mathrm{I}_{15 / 2} \rightarrow\left({ }^{4} \mathrm{~K}_{15 / 2},{ }^{4} \mathrm{G}_{9 / 2},{ }^{4} \mathrm{G}_{11 / 2}\right)$ absorption band integrated cross sections also turns out to be the only one to almost equal that of the highest experimental integrated cross sections $\left({ }^{4} \mathrm{I}_{15 / 2} \rightarrow{ }^{4} \mathrm{I}_{13 / 2}, \approx 44 \times 10^{-20} \mathrm{~cm}^{2} . \mathrm{nm}\right)$, it is clear that including or not the ${ }^{4} \mathrm{I}_{15 / 2} \rightarrow{ }^{4} \mathrm{G}_{11 / 2}$ transition in the refinement procedure affects mostly the $\Omega_{2}$-value in the normalized procedure, and a little bit the $\Omega_{4-}$ and $\Omega_{6}$-values in the unnormalized one.

\begin{tabular}{|c|c|c|c|c|}
\hline $\begin{array}{l}\text { Absorption } \\
\text { transition } \\
{ }^{4} I_{15 / 2} \rightarrow \\
\end{array}$ & Number & $\lambda_{\mathrm{av}}(\mathrm{nm})(*)$ & $\begin{array}{c}\text { Experimental } \\
\mathrm{S}^{\mathrm{ED}} \\
\left(10^{-20} \mathrm{~cm}^{2}\right)\end{array}$ & $\begin{array}{c}\text { Calculated } \\
S^{\mathrm{ED}} \\
\left(10^{-20} \mathrm{~cm}^{2}\right)\end{array}$ \\
\hline${ }^{4} \mathbf{I}_{13 / 2}$ & 1 & 1518.7 & 1.95191 & 1.70033 \\
\hline${ }^{4} I_{11 / 2}$ & 2 & 978.0 & 0.63096 & 0.53791 \\
\hline${ }^{4} \mathrm{I}_{9 / 2}$ & 3 & 809.7 & 0.33803 & 0.30834 \\
\hline${ }^{4} \mathrm{~F}_{9 / 2}$ & 4 & 655.3 & 1.35371 & 1.50901 \\
\hline${ }^{4} \mathrm{~S}_{3 / 2},{ }^{2} \mathrm{H}_{11 / 2}$ & 5,6 & 524.8 & 4.64197 & 5.59816 \\
\hline${ }^{4} \mathrm{~F}_{7 / 2}$ & 7 & 489.6 & 0.84593 & 0.87718 \\
\hline${ }^{4} \mathrm{~F}_{5 / 2},{ }^{4} \mathrm{~F}_{3 / 2}$ & 8,9 & 450.2 & 0.28853 & 0.32593 \\
\hline${ }^{2} \mathrm{H}_{9 / 2}$ & 10 & 407.7 & 0.25508 & 0.2438 \\
\hline $\begin{array}{ll}{ }^{4} \mathrm{G}_{11 / 2}, & { }^{4} \mathrm{G}_{9 / 2}, \\
{ }^{2} \mathrm{~K}_{15 / 2} & \end{array}$ & $11,12,13$ & 376.4 & 10.71863 & 7.73976 \\
\hline
\end{tabular}

Table 1. Data used in the Judd-Ofelt calculations. (*) $\lambda_{a v}$ was calculated according to the classical expression. $S^{E D}$ stands for "electric-dipole" oscillator "strength".

\begin{tabular}{|c|c|c|c|c|c|}
\hline Transition & $\begin{array}{c}\lambda_{\text {av }} \\
(\mathrm{nm})\end{array}$ & $\begin{array}{c}\mathrm{A}_{\mathrm{DE}} \\
\left(\mathrm{s}^{-1}\right)\end{array}$ & $\begin{array}{c}\mathrm{A}_{\mathrm{DM}} \\
\left(\mathrm{s}^{-1}\right)\end{array}$ & $\beta$ & $\begin{array}{c}\tau_{\mathrm{rad}} \\
(\mathrm{ms})\end{array}$ \\
\hline${ }^{4} \mathrm{I}_{13 / 2} \rightarrow{ }^{4} \mathrm{I}_{15 / 2}$ & 1518.7 & 157.51 & 68.04 & 1 & 4.433 \\
\hline${ }^{4} \mathrm{I}_{11 / 2} \rightarrow{ }^{4} \mathrm{I}_{5 / 2}$ & 977.8 & 217.67 & 0 & 0.8254 & 3.792 \\
$\rightarrow{ }^{4} \mathrm{I}_{13 / 2}$ & 2745.7 & 30.26 & 15.80 & 0.1746 & \\
\hline${ }^{4} \mathrm{I}_{9 / 2} \rightarrow{ }^{4} \mathrm{I}_{15 / 2}$ & 801.4 & 263.85 & 0 & 0.7955 & \\
$\rightarrow{ }^{4} \mathrm{I}_{13 / 2}$ & 1696.6 & 64.39 & 0 & 0.1941 & 3.015 \\
$\rightarrow{ }^{4} \mathrm{I}_{11 / 2}$ & 4442.1 & 1.42 & 2.02 & 0.0104 & \\
\hline${ }^{4} \mathrm{~F}_{9 / 2} \rightarrow{ }^{4} \mathrm{I}_{15 / 2}$ & 654.2 & 2435.84 & 0 & 0.9076 & \\
$\rightarrow{ }^{4} \mathrm{I}_{13 / 2}$ & 1149.4 & 136.48 & 0 & 0.0509 & 0.373 \\
$\rightarrow{ }^{4} \mathrm{I}_{11 / 2}$ & 1977.1 & 89.66 & 9.80 & 0.0371 & \\
$\rightarrow \rightarrow{ }^{4} \mathrm{I}_{9 / 2}$ & 3562.5 & 7.905 & 4.19 & $4.5068 \times 10^{-3}$ & \\
\hline${ }^{4} \mathrm{~S}_{3 / 2}+{ }^{2} \mathrm{H}_{11 / 2}$ & & & & & \\
$\rightarrow{ }^{4} \mathrm{I}_{15 / 2}$ & 541.4 & 38967.6 & 0 & 0.9424 & \\
$\rightarrow{ }^{4} \mathrm{I}_{13 / 2}$ & 841.3 & 1195.13 & 256.83 & 0.0351 & \\
$\rightarrow{ }^{4} \mathrm{I}_{11 / 2}$ & 1213.0 & 353.71 & 29.54 & $9.2685 \times 10^{-3}$ & 0.0242 \\
$\rightarrow{ }^{4} \mathrm{I}_{9 / 2}$ & 1668.6 & 458.29 & 2.21 & 0.0111 & \\
$\rightarrow{ }^{4} \mathrm{~F}_{9 / 2}$ & 3138.7 & 85.61 & 0.35 & $2.0789 \times 10^{-3}$ & \\
\hline${ }^{4} \mathrm{~F}_{7 / 2} \rightarrow{ }^{4} \mathrm{I}_{15 / 2}$ & 487.1 & 2830.0 & 0 & 0.7167 & \\
$\rightarrow{ }^{4} \mathrm{I}_{13 / 2}$ & 717.1 & 665.94 & 0 & 0.1687 & \\
$\rightarrow \rightarrow$ & 970.6 & 276.03 & 0 & 0.0699 & 0.253 \\
$\rightarrow{ }^{4} \mathrm{I}_{11 / 2}$ & 1241.9 & 135.42 & 12.88 & 0.0376 & \\
$\rightarrow{ }^{4} \mathrm{~F}_{9 / 2}$ & 1906.6 & 9.49 & 14.19 & $5.9961 \times 10^{-3}$ & \\
\hline$\Omega^{2} 6.338 \times 10$ &
\end{tabular}

$\Omega_{2}=6.338 \times 10^{-20} \mathrm{~cm}^{2}, \Omega_{4}=1.929 \times 10^{-20} \mathrm{~cm}^{2}, \Omega_{6}=0.943 \times 10^{-20} \mathrm{~cm}^{2}, \delta_{\mathrm{RMS}}=8.4$

Table 2. Judd-Ofelt parameters and spectroscopic factors of $\mathrm{Er}^{3+}$ cations in the "2 $\mathrm{ErF}_{3}$ "-doped glass sample.

Branching ratios and radiative lifetimes relevant for the ${ }^{4} \mathrm{I}_{13 / 2} \rightarrow, \quad{ }^{4} \mathrm{I}_{11 / 2} \rightarrow$ and $\left({ }^{2} \mathrm{H}_{11 / 2},{ }^{4} \mathrm{~S}_{3 / 2}\right) \rightarrow{ }^{4} \mathrm{I}_{15 / 2}$ emission bands calibration in cross section units were virtually unaffected by both the refinement procedure and the fact of taking into account or not the ${ }^{4} I_{15 / 2} \rightarrow{ }^{4} G_{11 / 2}$ transition. The results for the normalized procedure with the ${ }^{4} \mathrm{I}_{15 / 2} \rightarrow{ }^{4} \mathrm{G}_{11 / 2}$ transition included in the Judd-Ofelt analysis are shown in Table 2, and 
those for the other calculation procedures in the SI file (Tables 2-4). The $\delta_{\text {rms }}$ obtained (with normalization factor $\left.\sigma=0.025 \times \mathrm{S}_{\exp }\right), \approx 8.4$, is slightly higher than the typical values found in Goldner's work [46], especially for $\mathrm{Er}^{3+}$ ions, but still satisfactory given the fast convergence and stability of the refinement. The highest ratios of calculated electric-dipole transition strengths over measured ones were found on the ${ }^{4} \mathrm{I}_{15 / 2} \rightarrow\left({ }^{4} \mathrm{~S}_{3 / 2},{ }^{2} \mathrm{H}_{11 / 2}\right) \quad(\approx 1.2)$ and the ${ }^{4} \mathrm{I}_{15 / 2} \rightarrow\left({ }^{4} \mathrm{~K}_{15 / 2},{ }^{4} \mathrm{G}_{9 / 2},{ }^{4} \mathrm{G}_{11 / 2}\right)$ $(\approx 0.72)$ transitions (Table 5 of the SI file). The $\Omega_{2}=6.338 \times 10^{-}$ ${ }^{20} \mathrm{~cm}^{2}$ intensity parameter is close to those found in $\mathrm{Er}^{3+}: \mathrm{CaF}_{2}$ crystals [49] and $10 \mathrm{BaO}-5 \mathrm{PbF}_{2}-4 \mathrm{La}_{2} \mathrm{O}_{3}-\mathrm{Er}_{2} \mathrm{O}_{3}-80 \mathrm{TeO}_{2}$ [44] glass materials, but the $\Omega_{4}=1.929 \times 10^{-20} \mathrm{~cm}^{2}$ and $\Omega_{6}=0.943 \times 10^{-20} \mathrm{~cm}^{2}$ intensity parameters are closer to the values found in the $75 \mathrm{TeO}_{2}-15 \mathrm{GeO}_{2}-10 \mathrm{Nb}_{2} \mathrm{O}_{5}-5 \mathrm{Li}_{2} \mathrm{O}-$ 0.5 wt. $\% \mathrm{Er}_{2} \mathrm{O}_{3}$ [50] glass. In $\mathrm{Er}^{3+}: \mathrm{KPb}_{2} \mathrm{Cl}_{5}$ crystal, a higher $\Omega_{2}$-value was found $\left(7.63 \times 10^{-20} \mathrm{~cm}^{2}\right)$ together with lower $\Omega_{4}=1.68 \times 10^{-20} \mathrm{~cm}^{2}$ and $\Omega_{6}=0.43 \times 10^{-20} \mathrm{~cm}^{2}$ set of values [51]. These comparisons suggest qualitatively that $\mathrm{Er}^{3+}$ cations are bonded less covalently in our glass than in $\mathrm{KPb}_{2} \mathrm{Cl}_{5}$ crystals, but more covalently than in $\mathrm{CaF}_{2}$ crystals. And given the rather high $\Omega_{2}$ - and moderately high $\Omega_{6}$-values, we believe that $\mathrm{Er}^{3+}$ ions in our glass are partially surrounded by $\mathrm{F}^{-}$ anions, in a low point group symmetry local environment [52]. $\Omega_{2} / \Omega_{6}=6.72$ and $\Omega_{4} / \Omega_{6}=2.05$ stand among "high" ratios of intensity parameters, so-called spectroscopic-"quality" parameters, in this kind of glass materials. This favors branching ratios for transitions between multiplets ending on the ${ }^{4} \mathbf{I}_{13 / 2}$ level, as compared to those of transitions terminating on the ground state, which exhibits the highests $U^{(2,4,6)}$ matrix elements, for instance, ${ }^{4} \mathrm{I}_{11 / 2}$ and ${ }^{4} \mathrm{I}_{9 / 2}$ levels. In the heat-treated (and consequently partially crystallized) glass, the only intensity parameter that substantially increases is $\Omega_{2}$. According to [52], this could suggest that part of the $\mathrm{Er}^{3+}$ ions inserted in the nanocrystals become more surrounded by $\mathrm{O}^{2-}$ anions than $\mathrm{F}^{-}$ones, but this should be taken with pinches of salt because no corresponding covalency effect is observed through the $\Omega_{6}$ parameter.

\subsection{Excitation and emission spectroscopies at 80 $K$ and crystal field calculations}

Figure 4 displays the excitation spectrum of the ${ }^{4} S_{3 / 2},{ }^{4} I_{11 / 2}$ and ${ }^{4} \mathrm{I}_{13 / 2}$ levels emission spectra recorded at $80 \mathrm{~K}$ in the " $2 \mathrm{ErF}_{3}$ "doped and untreated glass. No peak position variation was observed between $300 \mathrm{~K}$ and $80 \mathrm{~K}$ (see Figure 2 of the SI file). Moreover, no effect of the heat-treatment nor of the $\mathrm{Er}^{3+}$ concentration on the peak positions was observed (see Figure 3 of the SI file).

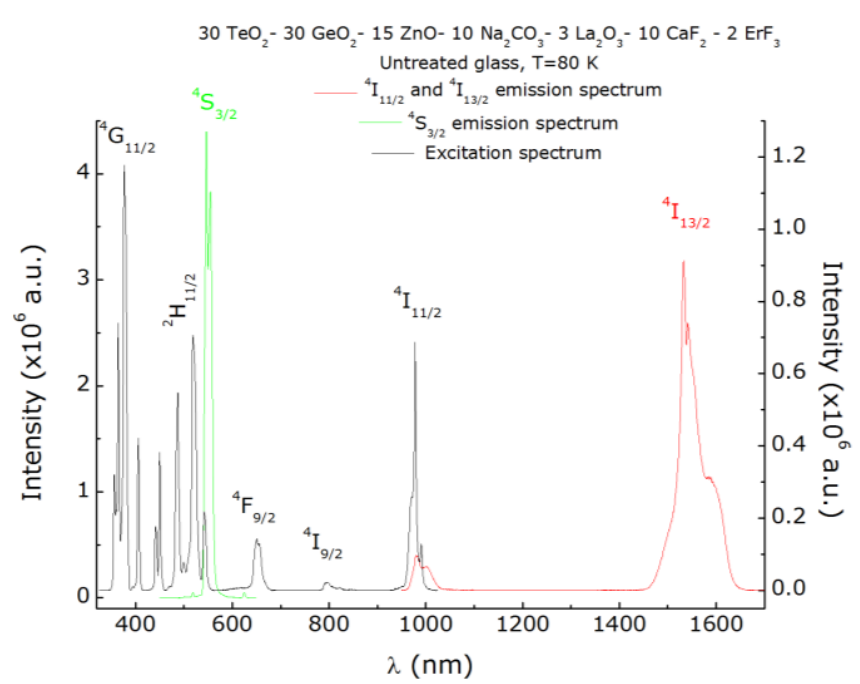

Figure 4. "2 $\mathrm{ErF}_{3}$ "-doped and thermally untreated glass excitation and emission spectra recorded at $80 \mathrm{~K}$.

In order to calculate the partition function of each multiplet and the crystal field strength, we used the energy levels of 6 multiplets ${ }^{2 \mathrm{~S}+1} \mathrm{~L}_{\mathrm{J}}$ of the $4 \mathrm{f}^{11} \mathrm{Er}^{3+}$ electronic configuration. They include 20 crystal field levels, experimentally determined from the emission and the excitation spectra recorded at $80 \mathrm{~K}$, of the ${ }^{4} \mathrm{I}_{15 / 2},{ }^{4} \mathrm{I}_{13 / 2},{ }^{4} \mathrm{I}_{11 / 2},{ }^{4} \mathrm{~F}_{9 / 2},{ }^{4} \mathrm{~S}_{3 / 2}$ and ${ }^{2} \mathrm{H}_{11 / 2}$ multiplets, and their 6 centroids (see Table 3 ), that were used as the input data in a parameterized Hamiltonian. The free-ion parameters chosen for our calculations were obtained from Carnall et al. [53] and already given in [51] and [54], as well as the expression of the crystal field Hamiltonian. The crystal field potential at the $\mathrm{Er}^{3+}$ ion sites was not known a priori, neither initial $\mathrm{B}_{\mathrm{q}}^{\mathrm{k}}$ parameters nor its point group. So, to initiate the calculations, we first noticed that the ground state $\left({ }^{4} I_{15 / 2}\right)$ experimentally looked like it was composed of 2 Kramers doublets (d) and 3 pseudo-quadruplets (q), the degeneracies of which were lifted by some $10-12 \mathrm{~cm}^{-1}$, positioned in a certain order (d-q-q-d-q). By trial and error using an Oh cubic group, we could simulate and reproduce approximately this energy level diagram $\left(\Gamma_{7}-\Gamma^{(1)}{ }_{8}-\Gamma^{(2)}{ }_{8}-\Gamma_{6}-\Gamma^{(3)}{ }_{8}\right)$. Then, a nonzero $\mathrm{B}_{0}{ }_{0}$ parameter was introduced using a $\mathrm{C}_{4 \mathrm{v}}$ point group, and let free to evolve to account roughly for the lifting of the pseudoquadruplets degeneracies. Subsequently, several point groups were tested $\left(\mathrm{C}_{4}, \mathrm{~S}_{4}, \mathrm{D}_{2 \mathrm{~d}}, \mathrm{C}_{3 \mathrm{v}}\right)$ and no rms deviation value lower than $\sim 20 \mathrm{~cm}^{-1}$ could be obtained, so that finally, a $\mathrm{C}_{2}$ Hamiltonian using the best $\mathrm{B}_{\mathrm{q}}^{\mathrm{k}}$ parameters refined in the previous stages was introduced. This firmly established low point group symmetry is remarkably consistent with the high $\Omega_{2}$ parameter value found in the Judd-Ofelt analysis. The set of $\mathrm{B}_{\mathrm{q}}^{\mathrm{k}}$ parameters was then varied by means of a least-squares procedure based on the 20 energy levels of the above- 
mentioned multiplets. The $\mathrm{B}_{\mathrm{q}}^{\mathrm{k}}$ 's which gave the best fit to the experimental energy levels, with a rms deviation value of 6.9 $\mathrm{cm}^{-1}$, are $\left(\right.$ in $\mathrm{cm}^{-1}$ ), $\mathrm{B}^{2}=891.315, \mathrm{~B}^{2}{ }_{2}=287.125, \mathrm{~B}_{0}{ }_{0}=84.297$, $\mathrm{ReB}_{2}{ }_{2}=106.943, \quad \mathrm{ImB}^{4}=-54.001, \quad \operatorname{ReB}_{4}{ }_{4}=45.729, \quad \operatorname{ImB}_{4}^{4}=-$ 86.293, $\quad \mathrm{B}^{6}{ }_{0}=-167.264, \quad \operatorname{ReB}^{6}{ }_{2}=43.215, \quad \operatorname{ImB}^{6}{ }_{2}=-16.669$, $\operatorname{ReB}_{4}^{6}=22.875, \quad \operatorname{ImB}_{4}^{6}=15.583, \quad \operatorname{ReB}_{6}^{6}=-14.120 \quad$ and $\operatorname{ImB}_{6}{ }_{6}=39.120$. The calculated and experimental energy levels are reported in Table 3.

\begin{tabular}{|c|c|c|c|c|c|}
\hline $\begin{array}{c}\mathrm{Er}^{3+} \\
\text { multiplet }\end{array}$ & $\begin{array}{l}\text { Experimental } \\
\text { results }\end{array}$ & $\begin{array}{c}\mathrm{CF} \\
\text { results }\end{array}$ & Centroid & $\begin{array}{c}\text { Crystal } \\
\text { field } \\
\text { splitting }\end{array}$ & $\begin{array}{c}\text { Partition } \\
\text { function } \\
\text { Z }\end{array}$ \\
\hline${ }^{4} \mathbf{I}_{15 / 2}$ & $\begin{array}{c}0.0,36.0 \\
46.8,82.0 \\
93.2,134.1 \\
220.6,229.6\end{array}$ & $\begin{array}{c}0.0,36.7 \\
50.9 \\
82.2 \\
96.7 \\
140.7 \\
221.1 \\
233.3 \\
\end{array}$ & 106.4 & 233.3 & 5.107 \\
\hline${ }^{4} \mathrm{I}_{13 / 2}$ & $\begin{array}{l}6523.2, \\
6635.7 \\
6684.5\end{array}$ & $\begin{array}{c}6525.8, \\
6555.3, \\
6579.8, \\
6601.4, \\
6631.7, \\
6691.5,6 \\
730.4\end{array}$ & 6615.3 & 204.6 & 4.764 \\
\hline${ }^{4} \mathbf{I}_{11 / 2}$ & $\begin{array}{l}\text { 10209.3, } \\
\text { 10261.7, } \\
10288.2\end{array}$ & $\begin{array}{l}10216.9, \\
10242.1, \\
10263.8, \\
10283.5, \\
10324.0, \\
10361.5\end{array}$ & 10280.2 & 144.6 & 4.509 \\
\hline${ }^{4} \mathbf{I}_{9 / 2}$ & 12500.0 & $\begin{array}{l}12495.3, \\
12515.1, \\
12536.6, \\
12546.9, \\
12555.1\end{array}$ & $12530.0^{(*)}$ & 59.8 & 4.261 \\
\hline${ }^{4} \mathrm{~F}_{9 / 2}$ & $\begin{array}{l}15372.8, \\
15420.2, \\
15479.9\end{array}$ & $\begin{array}{l}15376.3, \\
15425.3, \\
15478.5, \\
15508.4, \\
15572.4\end{array}$ & 15472.3 & 196.1 & 3.324 \\
\hline${ }^{4} S_{3 / 2}$ & 18298.3 & $\begin{array}{l}18300.0 \\
18415.4\end{array}$ & 18356.0 & 115.4 & 1.575 \\
\hline${ }^{2} \mathrm{H}_{11 / 2}$ & $\begin{array}{l}19267.8, \\
19286.4\end{array}$ & $\begin{array}{l}19268.9, \\
19283.6, \\
19287.5, \\
19296.5, \\
19302.6, \\
19315.6\end{array}$ & 19287.6 & 46.7 & 5.373 \\
\hline${ }^{4} \mathrm{~F}_{7 / 2}$ & 20512.8 & $\begin{array}{l}20515.9, \\
20617.5, \\
20669.0, \\
20745.1\end{array}$ & $20638.0^{(*)}$ & 229.2 & 2.427 \\
\hline${ }^{4} \mathrm{~F}_{5 / 2}$ & 22246.9 & $\begin{array}{l}22247.4, \\
22268.2, \\
22319.1\end{array}$ & $22287.0^{(*)}$ & 71.7 & 2.614 \\
\hline${ }^{4} \mathrm{~F}_{3 / 2}$ & 22650.1 & $\begin{array}{l}22650.7, \\
22801.3\end{array}$ & $22710.0^{(*)}$ & 150.6 & 1.486 \\
\hline${ }^{2} \mathrm{H}_{9 / 2}$ & 24630.5 & $\begin{array}{l}24628.2, \\
24655.0, \\
24667.0, \\
24683.3, \\
24716.0\end{array}$ & $24671.0^{(*)}$ & 87.8 & 4.134 \\
\hline${ }^{4} G_{11 / 2}$ & 26560.4 & $\begin{array}{l}26560.7, \\
26586.7, \\
26596.4, \\
26605.7,\end{array}$ & $26590.0^{(*)}$ & 62.0 & 5.037 \\
\hline
\end{tabular}

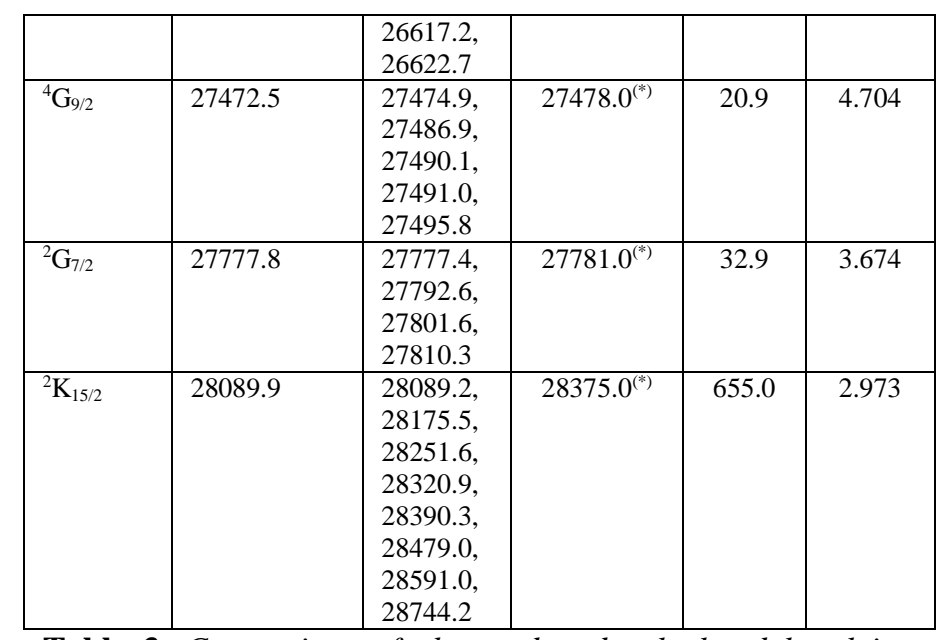

Table 3. Comparison of observed and calculated low-lying crystal field sublevel energies of the " $2 \mathrm{ErF}_{3}$ "-doped and untreated glass and calculated positions of upper-lying ones. Numbers in italics are those which were used in the crystal field parameters refinement. The other numbers were calculated a posteriori using the refined parameters and centroids together with manually fixed centroids marked by ${ }^{(*)}$. Except for the partition function column, all numbers are in $\mathrm{cm}^{-1}$.

All the wavefunctions calculated from this refinement were found to be composed of almost pure states $(\geq 99 \%$ of the ${ }^{2 S+1} L_{J}$ multiplet), except for the excited states of the thermalized $\left({ }^{4} \mathrm{~F}_{5 / 2} /{ }^{4} \mathrm{~F}_{3 / 2}\right)$ multiplets and the lowest crystal field sublevel of the ${ }^{2} \mathrm{G}_{7 / 2}$ multiplet, which exhibited a few $\%$ admixtures of ${ }^{4} \mathrm{~F}_{3 / 2}$ and ${ }^{4} \mathrm{~F}_{5 / 2}$ states, and ${ }^{4} \mathrm{G}_{9 / 2}$ state, respectively. The ${ }^{4} \mathbf{I}_{15 / 2,13 / 2,11 / 2,9 / 2}$ crystal field sublevels were even found purer than $99.9 \%$. In order to compare the crystal field strength exerted around the $\mathrm{Er}^{3+} 4 \mathrm{f}$ electrons with the one observed in such crystals as $\mathrm{KPb}_{2} \mathrm{Cl}_{5}$ or $\mathrm{Tl}_{3} \mathrm{PbBr}_{5}$, we calculated the $\mathrm{N}_{\mathrm{v}}$ number introduced by Auzel and Malta and found that the crystal field strength of this glass is about 1589 $\mathrm{cm}^{-1}$. This value stands almost exactly between the value found in $\mathrm{KPb}_{2} \mathrm{Cl}_{5}\left(1787 \mathrm{~cm}^{-1}\right)$ and the one estimated in $\mathrm{Tl}_{3} \mathrm{PbBr}_{5}\left(1326 \mathrm{~cm}^{-1}\right)$. In addition, all the multiplets crystal field splittings are much lower $\left(\leq 10 \%,{ }^{2} \mathrm{~K}_{15 / 2}\right.$ excluded) than the spin-orbit integral $\left(2376 \mathrm{~cm}^{-1}\right)$ of the $\mathrm{Er}^{3+}$ free-ion. Consequently, the ground state ${ }^{4} \mathrm{I}_{15 / 2}$ crystal field sublevels are likely to be fully populated at room and higher temperatures.

\section{$3.6 \mathrm{Er}^{3+}$ ions emission spectroscopy and fluorescence decays in the "2 $\mathrm{ErF}_{3}$ "-doped and untreated glass}

With the branching ratios and radiative lifetimes issued from the Judd-Ofelt analysis on the one hand (Section 3.4), the partition functions brought about by the crystal field 
calculations on the other hand (Section 3.5), we could calibrate the room temperature ${ }^{4} S_{3 / 2} \rightarrow,{ }^{4} I_{11 / 2} \rightarrow$ and ${ }^{4} I_{13 / 2} \rightarrow{ }^{4} I_{15 / 2}$ emission bands in cross section units, by both the FL and the reciprocity methods (RM). They are shown in Figure 5. They were derived experimentally by exciting the crystal at $380 \mathrm{~nm}$ for visible $\left({ }^{2} \mathrm{H}_{11 / 2},{ }^{4} \mathrm{~S}_{3 / 2}\right) \rightarrow{ }^{4} \mathrm{I}_{15 / 2}$ emission, or at $650 \mathrm{~nm}$ for ${ }^{4} \mathrm{I}_{11 / 2} \rightarrow{ }^{4} \mathrm{I}_{15 / 2}$ NIR and ${ }^{4} \mathrm{I}_{13 / 2} \rightarrow{ }^{4} \mathrm{I}_{15 / 2}$ IR emissions. Although the peak cross section values are typical of a non centrosymmetric environment, which forces the electricdipole mechanism to operate, and the spectra exhibit some "structure", the emission bands are so (inhomogeneously) broad that they are not resolved. The emission cross sections for the $\left({ }^{2} \mathrm{H}_{11 / 2},{ }^{4} \mathrm{~S}_{3 / 2}\right),{ }^{4} \mathrm{I}_{11 / 2}$ and ${ }^{4} \mathrm{I}_{13 / 2}$ multiplets increase slightly in the " $4 \mathrm{ErF}_{3}$ "-doped composition. In the " $2 \mathrm{ErF}_{3}$ "-doped glass, the effect of heat treatment is rather limited: it increases the emission cross sections of the $\left({ }^{2} \mathrm{H}_{11 / 2},{ }^{4} \mathrm{~S}_{3 / 2}\right)$ and ${ }^{4} \mathrm{I}_{11 / 2}$ levels but leaves unchanged the emission cross section of the ${ }^{4} \mathrm{I}_{13 / 2}$ level. However, the integrated emission of the ${ }^{4} \mathrm{I}_{13 / 2}$ level displays a different temperature dependence in the glassy ceramics and in the glass material. The data shown in Figure 6 of the SI file for the "2 $\mathrm{ErF}_{3}$-doped" samples show that the thermal quenching is less pronounced in the glassy ceramics than in the glass material. This could suggest that part of the $\mathrm{Er}^{3+}$ ions dissolved in the nanocrystals. The radiative lifetime refined in such a way that the FL- and RM-calibrated ${ }^{4} \mathrm{I}_{11 / 2}$ and ${ }^{4} \mathbf{I}_{13 / 2}$ emission spectra, match approximately together at the zero-phonon wavelength, is $\approx 16.6$ and $9.9 \mathrm{~ms}$, respectively. As compared to the values found by the Judd-Ofelt calculations, these values are unreasonable but nevertheless, this discrepancy set aside, both RM- and FL- spectra agree in peak positions, widths and relative intensities for the ${ }^{4} \mathrm{I}_{11 / 2}$ and the ${ }^{4} \mathrm{I}_{13 / 2}$ levels.

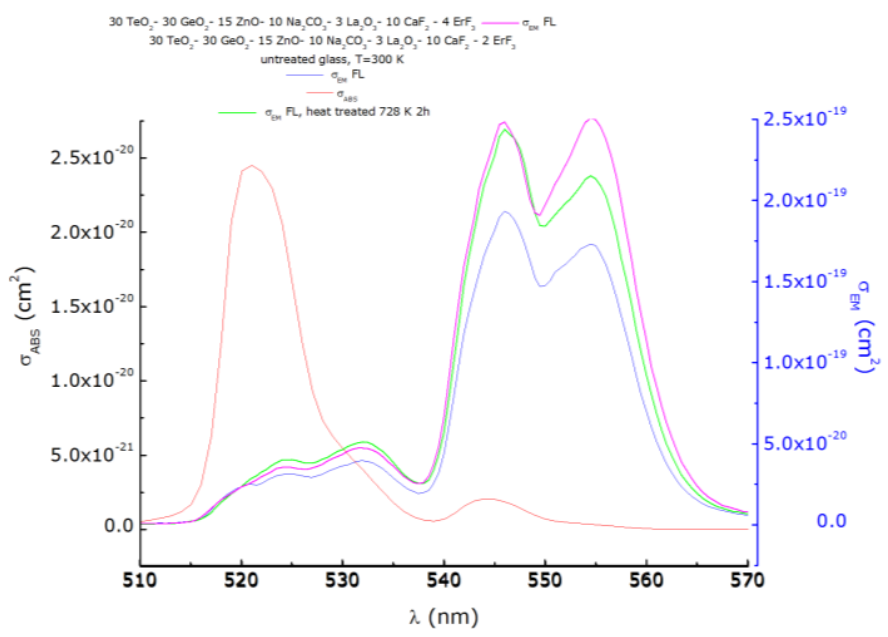

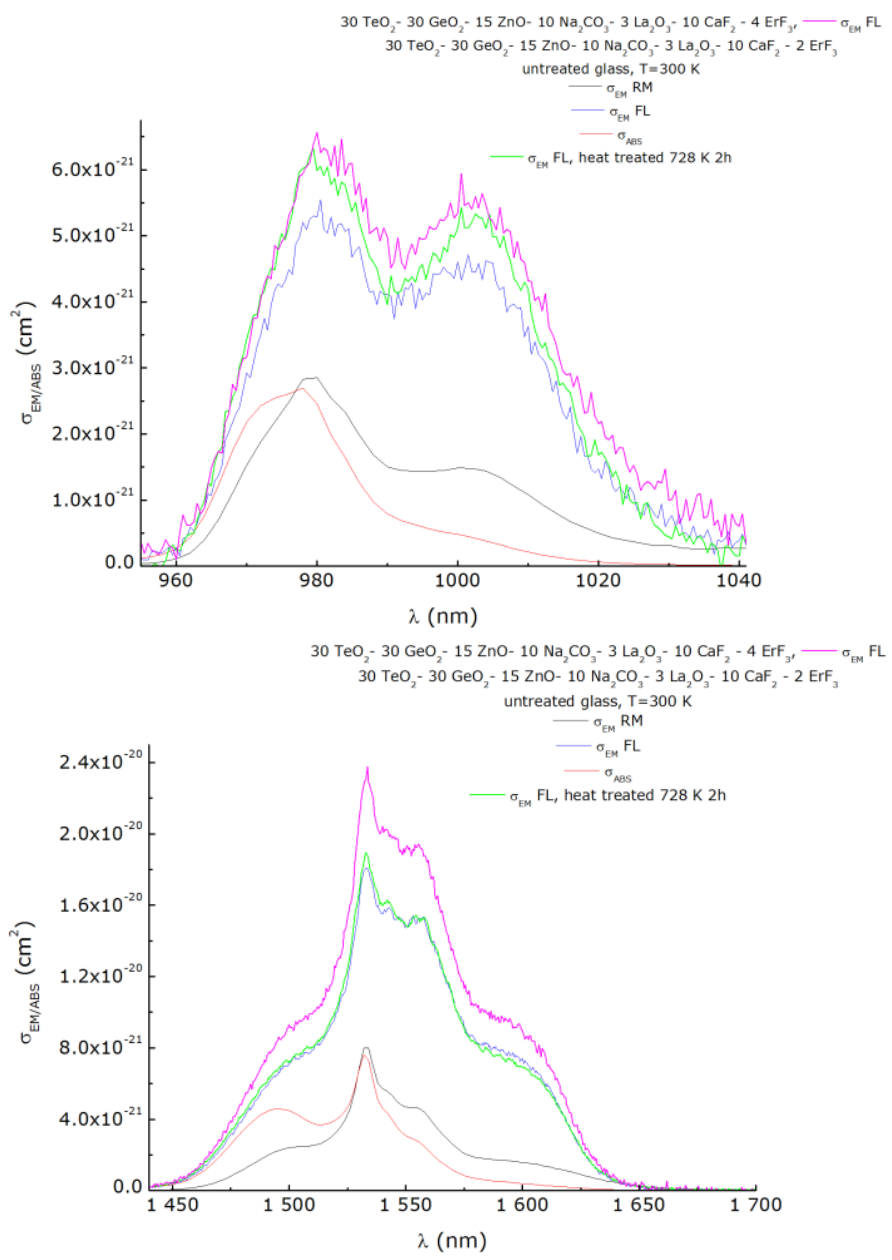

Figure 5. Absorption, RM- and FL-calibrated emission spectra in $\mathrm{Er}^{3+}$-doped glasses and glass-ceramics. Emission spectra were obtained by exciting at $380 \mathrm{~nm}$ the visible $\left({ }^{2} H_{11 / 2},{ }^{4} S_{3 / 2}\right) \rightarrow{ }^{4} I_{15 / 2}$ emission, or by exciting at $650 \mathrm{~nm}$ the ${ }^{4} I_{11 / 2} \rightarrow{ }^{4} I_{15 / 2}$ NIR and ${ }^{4} I_{13 / 2} \rightarrow{ }^{4} I_{15 / 2}$ IR emissions.

$\mathrm{Er}^{3+}$ ions fluorescence decays as a function of temperature in "2 $\mathrm{ErF}_{3}$ "-doped glasses shown in figure 6 can be fitted to an exponential law over time ranges which vary with the emission level: $4,0.1$ and 2 times $\tau_{\text {rad }}$ for the ${ }^{4} S_{3 / 2},{ }^{4} I_{11 / 2}$ and ${ }^{4} \mathrm{I}_{13 / 2}$ multiplets, respectively. The resulting experimental lifetimes lead to fluorescence quantum yields of 3.4 and $67.2 \%$ for the two latter levels, reflecting the overall possible effects of intrinsic non radiative decays and quenching by impurities. The heat treatment on the " $2 \mathrm{ErF}_{3}$ "-doped composition does not affect the ${ }^{4} \mathrm{~S}_{3 / 2}$ lifetime, but increases slightly that of the ${ }^{4} I_{11 / 2}$ level and substantially that of the ${ }^{4} I_{13 / 2}$ level (by a factor $\times 1.4$ ). On the other hand, the lifetimes of the ${ }^{4} \mathrm{~S}_{3 / 2},{ }^{4} \mathrm{I}_{11 / 2}$ and ${ }^{4} \mathrm{I}_{13 / 2}$ levels at room temperature decrease drastically with the increase in dopant concentration (Figs. 4 and 5 of the SI file). This is likely to be due to quenching by impurities. 

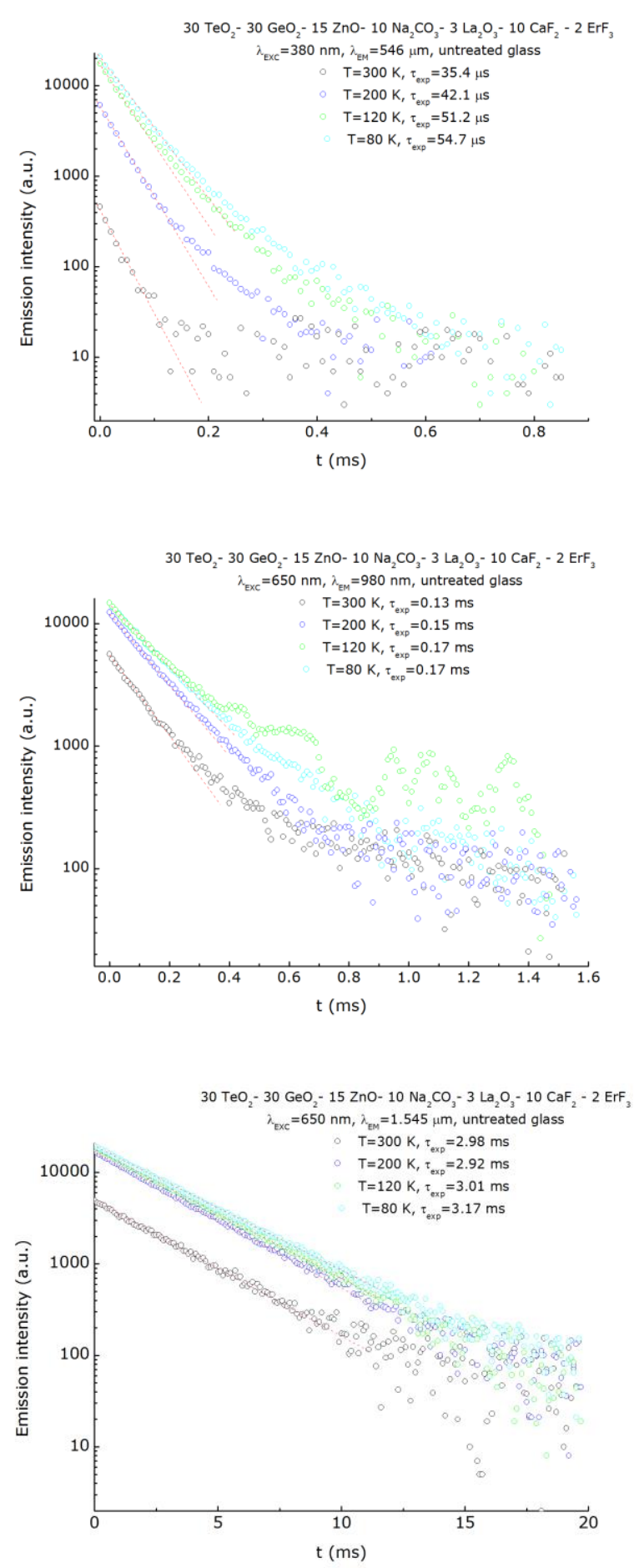

Figure 6. $E r^{3+}$ ions fluorescence decays at $\lambda_{\text {em }}=456\left({ }^{4} S_{3 / 2}\right)$, $980\left({ }^{4} I_{11 / 2}\right)$ and $1545\left({ }^{4} I_{13 / 2}\right) \mathrm{nm}$ in the "2 $\mathrm{ErF}_{3}$ "-doped and untreated glass as a function of temperature.

\subsection{Magnetic susceptibility of Er ${ }^{3+}$-doped glass and glassy ceramics}

Another way to investigate the potential impact of structural changes near the $\mathrm{Er}^{3+}$ cations is to measure the magnetic susceptibility of the glass and the glassy ceramics as a function of temperature, and cycling around the crystallization temperature. Figure 7 shows the magnetic susceptibility measurements (in the MKSA units system) of the " $2 \mathrm{ErF}_{3}$ "and " $4 \mathrm{ErF}_{3}$ "-doped glasses. The excitation and emission spectroscopies (Fig. 4) combined with crystal field calculations (Table 3 ) established that the ground state $\left({ }^{4} I_{15 / 2}\right)$ energy splitting is $335 \mathrm{~K}$, which is smaller than both the spinorbit integral and the thermal activation energy scanned in our measurements (300-950 K), but however much higher than the magnetic characteristic energy due to the applied magnetic field, typically $\mathrm{Jg}_{\mathrm{J}} \mu_{\mathrm{B}} \mu_{0} \mathrm{H} / \mathrm{k}_{\mathrm{B}} \sim 6 \mathrm{~K}$.

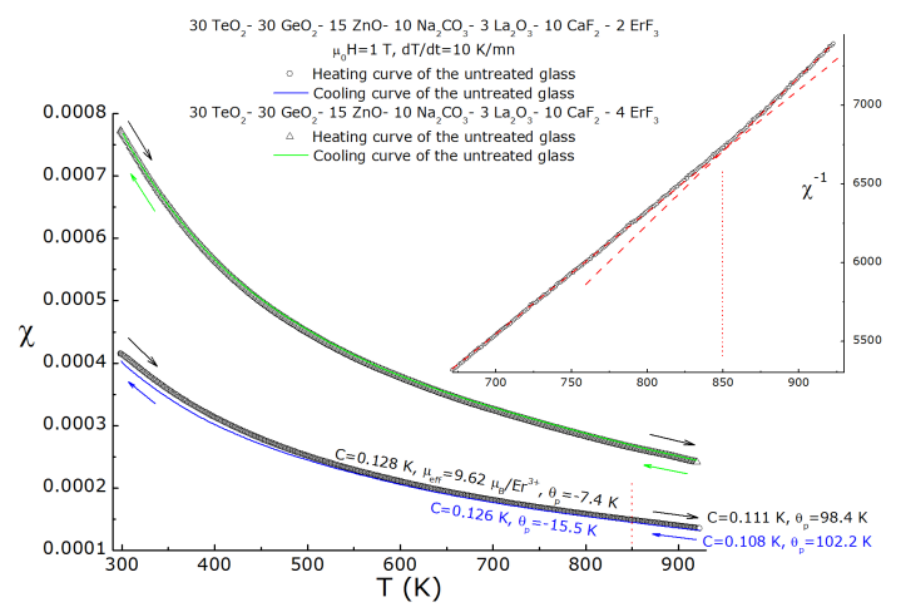

Figure 7. MKSA magnetic susceptibility of "2 $\mathrm{ErF}_{3}$ "- and "4 $\mathrm{ErF}_{3}$ "'-doped glasses, measured upon cycling around the crystallization temperature, and zoom of the high temperature inverse magnetic susceptibility of the former glass. Between the black and the blue curves, a $15 \mathrm{mn}$-long stage at $930 \mathrm{~K}$ is applied.

These energy considerations explain why, contrary to the $\mathrm{Yb}^{3+}$-doped glass analog [26], the paramagnetic susceptibility curves shown in Fig. 7 can all be fitted to a Curie-Weiss (CW) law from room temperature to $800 \mathrm{~K}$. Note that $800 \mathrm{~K}$ is 50 degrees above the crystallization temperature. In the " $2 \mathrm{ErF}_{3}$ "doped glass, this $\mathrm{CW}$ behavior is characterized by an effective magnetic moment of $\approx 9.62 \mu_{\mathrm{B}} / \mathrm{Er}^{3+}$, equal, given the error bar, to the theoretical free ion value, and it is characterized by slightly antiferromagnetic (AFM) interactions between the $\mathrm{Er}^{3+}$ cations $\left(\theta_{\mathrm{p}}=-7.4 \mathrm{~K}\right)$. At some higher temperature, close to $850 \mathrm{~K}$, a change of paramagnetic behavior is observed in which the Curie constant decreases slowly but above all the magnetic interactions between $\mathrm{Er}^{3+}$ cations become substantially ferromagnetic (FM), with one order of magnitude gain in absolute value of the Curie paramagnetic 
temperature, $\theta_{\mathrm{p}}=+98.4 \mathrm{~K}$. After the 15 minutes stage at $930 \mathrm{~K}$, the system exhibits the same $\mathrm{CW}$ behavior (same Curie constant and slightly larger paramagnetic Curie temperature) and reversibly "switch back" to a CW behavior around $850 \mathrm{~K}$ where the $\mathrm{C}$ constant is the same as upon heating and the paramagnetic Curie temperature is again negative $\left(\theta_{\mathrm{p}}=-15.5\right.$ $\mathrm{K}$, keeping in mind that this effect is not due to the change in volumic mass of the sample, which was taken into account in the calibration procedure of the magnetic susceptibility in MKSA units). This seemingly and almost reversible behavior suggests that the $\mathrm{Er}^{3+}$ cations initially dissolved in the glass undergo some local structure changes leading to a doubling of the Curie temperature. Even if $T_{g}$ and $T_{c}$ could not be directly detected on the magnetic $\chi$ versus temperature curve, these measurements suggest that the high temperature paramagnetic behavior is dominated by those $\mathrm{Er}^{3+}$ cations which are dissolved in the nanocrystallites. The change of sign (from AFM to FM) of the $\mathrm{Er}^{3+}$ magnetic interactions is striking and difficult to explain solely from these data. As a matter of fact, in $\mathrm{Er}^{3+}$-doped $\mathrm{CaF}_{2}$ crystals, the first and second order Zeeman contributions to the overall magnetic susceptibility can lead to FM and AFM interactions, respectively [55], and the net balance depends on $\mathrm{Er}^{3+}$ cations concentration and possible clusters formation. The same phenomenological behavior was observed in the $4 \mathrm{ErF}_{3}$-doped glass.

\section{Conclusions}

New $\mathrm{Er}^{3+}$-doped oxyfluorogermanotellurate glasses have been synthesized and submitted to varied heat treatments to provoke crystallization in their matrix. The nanocrystallites formed have been found to measure typically $50 \AA$ and likely to be of $\mathrm{Er}^{3+}$-doped $\mathrm{CaF}_{2}$, by XRD, HRTEM, EDS, SAED, optical spectroscopy and VSM techniques. Heat treatment increases $\mathrm{Er}^{3+}$ ions emission cross section at 546 and $980 \mathrm{~nm}$ but does not affect it at $1.5 \mu \mathrm{m}$, although it increases the experimental lifetime of the ${ }^{4} \mathrm{I}_{13 / 2}$ level. Cycling around the crystallization temperature with a VSM shows some kind of "crossover" between the Curie-Weiss behavior of the $\mathrm{Er}^{3+}$ cations dissolved in the glass and those dissolved in the nanocrystallites with a striking change of magnetic interactions sign from anti- to ferromagnetic. Judd-Ofelt analysis led to the following intensity parameters $\Omega_{2}=6.338 \times 10^{-20} \mathrm{~cm}^{2}, \Omega_{4}=1.929 \times 10^{-20} \mathrm{~cm}^{2}, \Omega_{6}=0.943 \times 10^{-20}$ $\mathrm{cm}^{2}$, and the rather high $\Omega_{2}$-value was found consistent with crystal field calculations with a refined parameterized Hamiltonian of $\mathrm{C}_{2}$-symmetry, which eventually permitted to estimate the crystal field strength in this glass, $N_{v}=1589 \mathrm{~cm}^{-1}$.

\section{Acknowledgments}

Hayat Zanane is the owner of a PROFAS B program fellowship of the French and Algerian Ministries of Foreign Affairs.

\section{References}

[1] X. Qiao, X. Fan, M. Wang, X. Zhang, Opt. Mater. 27 (2004) 59.

[2] Wang Y and Ohwaki J, Appl. Phys. Lett. 63 (1993) 3268.

[3] Dejneka M J, J. Non-Cryst. Solids 239 (1998) 149.

[4] Fu J, Parker J M, Flower P S and Brown R M, MRS Bull. 37 (2002) 1843.

[5] Lahoz F, Martin I R and Mendez-Ramos J 2004 J. Chem. Phys., 120 (2004) 6180.

[6] R. A. H. El-Mallawany, Tellurite Glasses HandbookPhysical Properties and Data, (CRC Boca Raton, FL 2001).

[7] Hiliang Kang, Xiudi Xiao, Qiwen Pan, Dongdan Chen, JianrongQiu and Guoping Dong, Scientific Reports, 7 (2017) 43186.

[8] Z. Pan, S.H. Morgan, J. Non-Cryst. Solids, 210 (2-3) (1997) 130.

[9] Wenhua Tang, Ying Tian, Bingpeng Li, Yayan Xu, Qunhuo Liu, Junjie Zhang, Shiqing $\mathrm{Xu}$, Ceramics International, 45 (13) (2019) 16411-16416.

[10] Y. Luo, J. Zhang, J. Sun, S. Lu, X. Wang, Optical Materials 28 (2006) 255-258.

[11] J. Sun, J. Zhang, Y. Luo, S. Lu, X. Ren, B. Chen, X. Wang, Optical Materials 28 (2006) 306-309.

[12] Aiswarya Dash, Sumit Kumar Pal, Indranil Banerjee, Subhabrata Chakraborty, Int. J. Appl. Ceram. Techno., 15 (2007) 223-231.

[13] Zhou L, Chen D, Luo W, Wang Y, Yu Y, Liu F, Mater Lett 61 (2007) 3988-3990.

[14] Chen D, Wang Y, Yu Y, et al, Mater Chem Phys 95 (2006) 264-269.

[15] A. Miguel, R. Morea, M.A. Arriandiaga, M. Hernandez, F.J. Ferrer C. Domingo, J.M. Fernandez-Navarro, J. Gonzalo, J. Fernandez, R. Balda, J Eur Ceram Soc 34 (2014) 3959-3968.

[16] Chunlei Yu, Junjie Zhang, Lei Wen, Zhonghong Jiang, Materials Letters 61 (2007) 3644-3646.

[17] Zhongjian Hu, Yuansheng Wang, En Ma, Feng Bao, Yunlong Yu, Daqin Chen, Materials Research Bulletin 41 (2006) 217-224.

[18] Zhao-xiaHou, Zhao-luXue, Shao-hong, Wang, Journal of Alloys and Compounds 514 (2012) 109 - 112.

[19] William J. Miniscalco, Journal of Lightwave Technology, 9 (1991) 234-250. 
[20] Ying Guana, Zhihao Wei, Yanlin Huang, Ramzi Maalej, Hyo Jin Seo, Ceramics International 39 (2013) 70237027.

[21] H. Chen, Y. H. Liu, Y. F. Zhou, Z. H. Jiang, Journal of Alloys and Compounds 397 (2005) 286 -290.

[22] A. Jain, R. Pankajavalli, R. Babu, S. Anthonysamy, J. Therm. Anal. Calorim. 115 (2014) 1279-1287.

[23] T.S. Lakshmi Narasimhan, M. Sai Baba, R. Viswanathan, Thermochim. Acta 427 (1-2) (2005) 137147.

[24] L. F. S. Gonçalo Monteiro, Luís F. Santos, J.C.G. Pereira, Rui M. Almeida, Journal of Non-Cryst. Solids 357 (2011) 2695-2701.

[25] B. L. Shivachev, T. Petrov, H. Yoneda, R. Titorenkova, B. Mihailova, Scripta Materialia 61 (2009) 493-496.

[26] Hayat Zanane, Matias Velázquez, Dominique Denux, Philippe Goldner, Alban Ferrier, Aïcha Kermaoui, Hamid Kellou, Michel Lahaye, Sonia Buffière, François Weill, Optical Materials, 90 (2019) 108-117.

[27] H. Zhao-xia, L. Hang-xin, X. Zhao-lu, W. Mei-han, H. Xiao-dan, W. Shao-hong, J.Alloy. Comp. 640 (2015) 311.

[28] Z. Zhao-xiaHou, Zhao-luXue, Shao-hong Wang, J. Alloy. Comp. 514 (2012) 109.

[29] Zhurova, E.A.; Maximov, B.A.; Simonov, V.I.; Sobolev, B.P.; Kristallografiya, 41 (3) (1996) 438-443.

[30] P. Scherrer, Nach. Gesell. Wissens. Gott, Math. Phys. (1-2) (1918) 96.

[31] Daqin Chen, Yuansheng Wang, Yunlong Yu, En Ma, Feng Bao, Zhongjian $\mathrm{Hu}$, Yao Cheng. Materials Chemistry and Physics 95 (2006) 264-26977.

[32] M. Mortier, F. Auzel, Journal of Non-Crystalline Solids 256-257 (1999) 361-365.

[33] W. J. Miniscalco, Journal of Lightwave Technology 9 (2) (1991) 234-250.

[34] B.R. Judd, Phys. Rev., 127 (1962) 750.

[35] G.S. Ofelt, J. Chem. Phys., 37 (1962) 511.

[36] E. S. Sazali, R. Sahar, S. K. Ghoshal, S. Rohani, R. Arifin, Journal of Non-Oxide Glasses 6 (2014) 61 - 67.

[37] K. Ouannes, M.T. Soltani, M. Poulain, G. Boulon, G. Alombert-Goget, Y. Guyot, A. Pillonnet, K. Lebbou, J. of Alls and Comp 603 (2014) 132-135.

[38] P. Babu, H.J. Seo, C.R. Kesavulu, K.H. Jang, C.K. Jayasankar, J. Lumin., 129 (2009) 444-448.

[39] R.Rolli, M. Montagna, S. Chaussedent, A. Monteil, V.K Tikhomirov, M. Ferrari, Opt. Mat 21 (2003) 743-748.

[40] S. Xy, Z.Yang, G. Wang, S. Dai, J. Zhang, L. Hu, Z. Jiang, J. of All. and Comp.377 (2004) 253-258.

[41] Tanabe S, Ohyagi T, Soga N and Hanada T, Phys. Rev. B 46 (1992) 3305.
[42] Tanabe S, Hayash H, Hanada T and Onodera N, Opt. Mater. 19 (2002) 343-349.

[43] Heidepriem H E, Ehrt D, Bettinelli M and Speghini A, J. Non-Cryst. Solids 240 (1998) 66-78.

[44] Dhiraj K. Sardar, Douglas M. Dee, Kelly L. Nash, Raylon M. Yow, and John B. Gruber, Journal of Applied Physics 102 (2007) 083105, 1-6.

[45] Daqin Chen, Yuansheng Wang, Yunlong Yu, En Ma and Zhongjian Hu, J. Phys.: Condens. Matter 17 (2005) 65456557.

[46] Ph. Goldner, Mol. Phys., 101 (7) (2003) 903-908.

[47] Jorgensen C K and Judd B R 1964 Mol. Phys. 8 (1964) 281.

[48] F. Auzel, J. All. \& Comp., 380 (2004) 9-14.

[49] G. A. Kumar, Richard Riman, S. C. Chae, Y. N. Jang, I. K. Bae and H. S. Moon, Journal of Applied Physics 95 (2004) 3243.

[50] Xiang Shen, Qiuhua Nie, Xunsi Wang, IEEE International Conference on Industrial Informatics 2006.

[51] A. Ferrier, M. Velázquez, J. L. Doualan, and R. Moncorgé, J. Opt. Soc. Am. B 24 (2007) 2526.

[52] Xvsheng Qiao, Xianping Fan, Minquan Wang, Jean-Luc Adamand Xianghua Zhang, J. Phys: Condens. Matter 18 (2006) 6937-6951.

[53] W. T. Carnall, G. L. Goodman, K. Rajnak, R. S. Rana, J. Chem. Phys., 90 (7) (1989) 3443-3457.

[54] A. Ferrier, M. Velázquez and R. Moncorgé, Phys. Rev. B, 77 (2008) 075122, 1-11.

[55] Kumar et al., Chem. Phys. Lett., 33 (1) (1975) 181-185. 